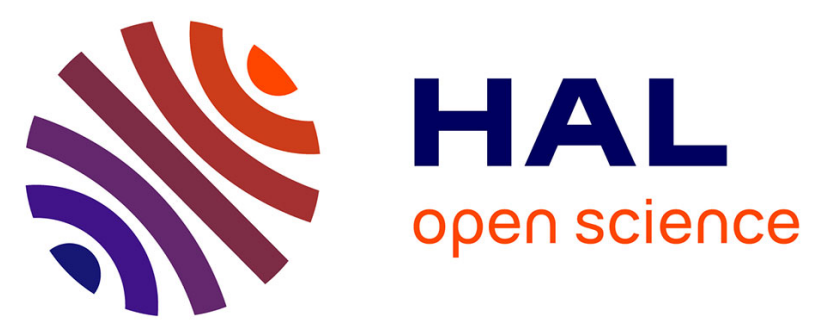

\title{
X-ray absorption spectroscopy evidence of sulfur-bound cadmium in the Cd-hyperaccumulator Solanum nigrum and the non-accumulator Solanum melongena
}

Marie-Laure Pons, Blanche Collin, Emmanuel Doelsch, Perrine Chaurand, Till Fehlauer, Clément Levard, Catherine Keller, Jérôme Rose

\section{To cite this version:}

Marie-Laure Pons, Blanche Collin, Emmanuel Doelsch, Perrine Chaurand, Till Fehlauer, et al.. Xray absorption spectroscopy evidence of sulfur-bound cadmium in the Cd-hyperaccumulator Solanum nigrum and the non-accumulator Solanum melongena. Environmental Pollution, 2021, 279, pp.116897. 10.1016/j.envpol.2021.116897 . hal-03184158

\author{
HAL Id: hal-03184158 \\ https://hal.science/hal-03184158
}

Submitted on 29 Mar 2021

HAL is a multi-disciplinary open access archive for the deposit and dissemination of scientific research documents, whether they are published or not. The documents may come from teaching and research institutions in France or abroad, or from public or private research centers.
L'archive ouverte pluridisciplinaire HAL, est destinée au dépôt et à la diffusion de documents scientifiques de niveau recherche, publiés ou non, émanant des établissements d'enseignement et de recherche français ou étrangers, des laboratoires publics ou privés. 


\section{Journal Pre-proof}

X-ray absorption spectroscopy evidence of sulfur-bound Cadmium in the Cdhyperaccumulator Solanum nigrum and the non-accumulator Solanum melongena

Marie-Laure Pons, Blanche Collin, Emmanuel Doelsch, Perrine Chaurand, Till Fehlauer, Clément Levard, Catherine Keller, Jérôme Rose

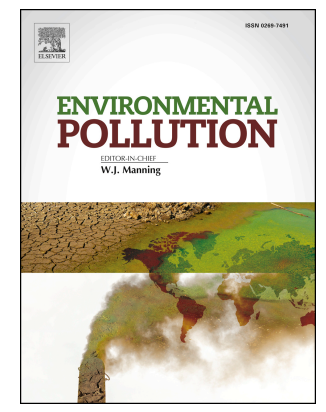

PII:

S0269-7491(21)00479-6

DOI:

https://doi.org/10.1016/j.envpol.2021.116897

Reference: ENPO 116897

To appear in: Environmental Pollution

Received Date: 3 December 2020

Revised Date: 24 February 2021

Accepted Date: 2 March 2021

Please cite this article as: Pons, M.-L., Collin, B., Doelsch, E., Chaurand, P., Fehlauer, T., Levard, C., Keller, C., Rose, J., X-ray absorption spectroscopy evidence of sulfur-bound Cadmium in the Cdhyperaccumulator Solanum nigrum and the non-accumulator Solanum melongena, Environmental Pollution, https://doi.org/10.1016/j.envpol.2021.116897.

This is a PDF file of an article that has undergone enhancements after acceptance, such as the addition of a cover page and metadata, and formatting for readability, but it is not yet the definitive version of record. This version will undergo additional copyediting, typesetting and review before it is published in its final form, but we are providing this version to give early visibility of the article. Please note that, during the production process, errors may be discovered which could affect the content, and all legal disclaimers that apply to the journal pertain.

(c) 2021 Elsevier Ltd. All rights reserved. 


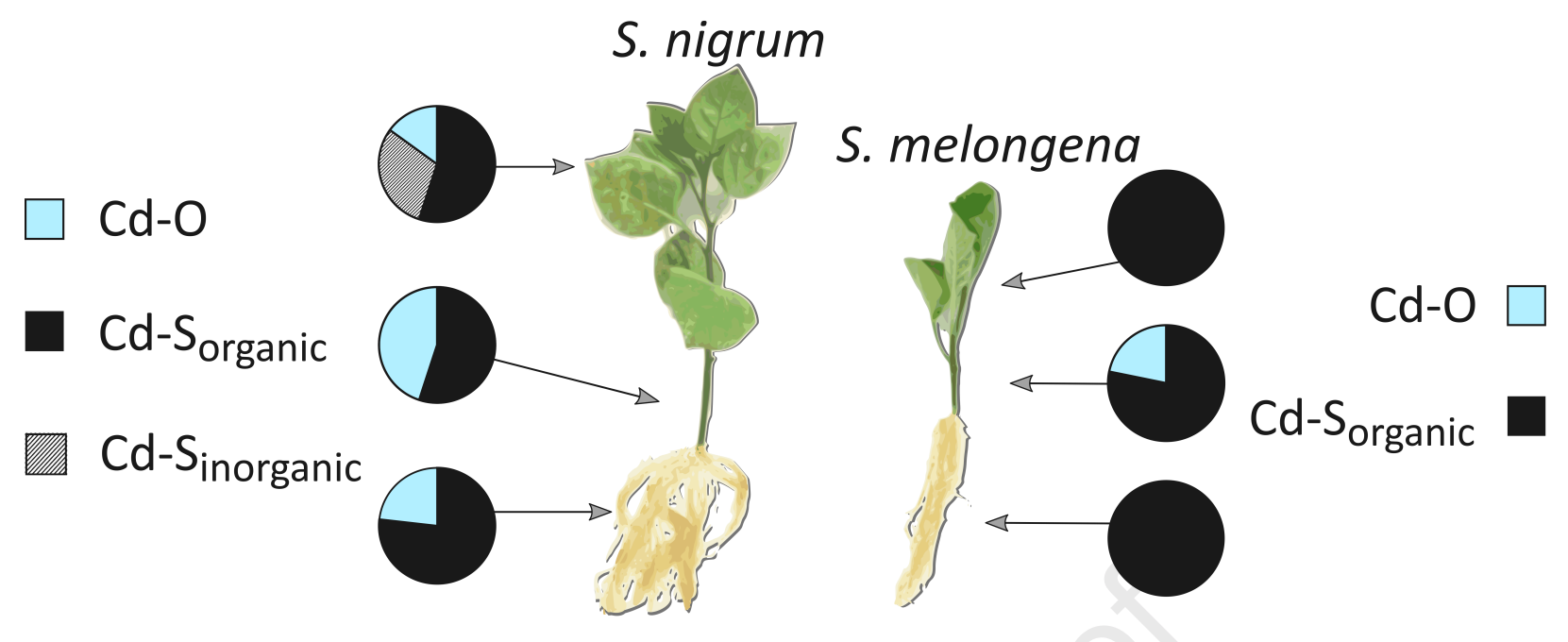




\section{X-ray absorption spectroscopy evidence of sulfur-bound Cadmium} in the Cd-hyperaccumulator Solanum nigrum and the non-

\section{accumulator Solanum melongena}

4

5 Marie-Laure Pons ${ }^{a 1^{\star}}$, Blanche Collin ${ }^{a}$, Emmanuel Doelsch $^{\mathrm{b}}$, Perrine Chaurand $^{\mathrm{a}}$, Till

6 Fehlauer $^{\mathrm{a}}$, Clément Levard ${ }^{\mathrm{a}}$, Catherine Keller ${ }^{\mathrm{a}}$ and Jérôme Rose ${ }^{\mathrm{a}}$

7 a: Aix Marseille Univ, CNRS, IRD, INRAE, Coll France, CEREGE UMR 7330, Aix en

8 Provence, France

9 b: CIRAD, UPR Recyclage et risque, F-34398 Montpellier, France Recyclage et Risque,

10 Univ Montpellier, CIRAD, Montpellier, France

11

12 Corresponding author. Marie-Laure Pons* pons@cerege.fr

13

14

15

\footnotetext{
${ }^{1}$ Permanent email address: dr.marie.laure.pons@gmail.com
} 


\section{Abstract}

It has been proposed that non-protein thiols and organic acids play a major role in cadmium phytoavailability and distribution in plants. In the Cd-hyperaccumulator Solanum nigrum and non-accumulator Solanum melongena, the role of these organic ligands in the accumulation and detoxification mechanisms of $\mathrm{Cd}$ are debated. In this study, we used Xray absorption spectroscopy to investigate $\mathrm{Cd}$ speciation in these plants (roots, stem, leaves) and in the soils used for their culture to unravel the plants responses to Cd exposure. The results show that $\mathrm{Cd}$ in the $100 \mathrm{mg} \cdot \mathrm{kg}^{-1} \mathrm{Cd}$-doped clayey loam soil is sorbed onto iron oxyhydroxides. In both $S$. nigrum and $S$. melongena, Cd in roots and fresh leaves is mainly bound to thiol ligands, with a small contribution of inorganic $S$ ligands in S. nigrum leaves. We interpret the $\mathrm{Cd}$ binding to sulfur ligands as detoxification mechanisms, possibly involving the sequestration of $\mathrm{Cd}$ complexed with glutathione or phytochelatins in the plant vacuoles. In the stems, results show an increase binding of Cd to $-\mathrm{O}$ ligands ( $>50 \%$ for $S$. nigrum). We suggest that $\mathrm{Cd}$ is partly complexed by organic acids for transportation in the sap.

\section{Capsule}

Cadmium speciation in Solanaceae was investigated using X-ray absorption spectroscopy. Results showed evidence of $\mathrm{Cd}$ detoxification through $\mathrm{Cd}$ binding with thiols and inorganic sulfur.

\section{Keywords}

Cadmium, Speciation, Toxicity, Solanaceae, X-ray absorption spectroscopy. 
43 Cadmium contamination in agricultural soils has raised worldwide concerns, as its release 44 in the environment dramatically increased in the past decades due to various anthropogenic activities such as smelting, combustion of coal or inorganic phosphate fertilization (Cai et al., 2003; Cullen and Maldonado, 2013; Dharma-wardana, 2018; Zhou and Song, 2004). Cadmium is toxic toward almost all forms of life, even at low concentrations (Cullen and Maldonado, 2013; Das et al., 1997). With relatively high mobility in the soil/plant system, Cd easily enters the food chain and poses human health

50 threats (Cullen and Maldonado, 2013; Das et al., 1997). Previous studies have 51 demonstrated that the mobility and bioavailability of $\mathrm{Cd}$ in the soil/plant system - thus its 52 toxicity in this system - depends ultimately on its chemical speciation (Cullen and 53 Maldonado, 2013).

54 The development of direct, experimental characterization of trace elements speciation by 55 X-ray absorption spectroscopy (XAS) has brought key information on trace metal behavior in the critical zone (Collin et al., 2014; Doelsch et al., 2006; Huguet et al., 2012; Isaure et al., 2015; Sarret, 2002; Sarret et al., 2013). However, applying this methodology to the determination of $\mathrm{Cd}$ speciation in biological samples remains challenging as in most plants, Cd concentration (e.g. $0.01-1 \mathrm{mg}^{\mathrm{kg}}{ }^{-1}$ dry weight) lies below the technical detection

60 limit of most X-ray absorption synchrotron beamlines. That is why, to date, Cd speciation 61 determination has mainly been carried out on Cd-hyperaccumulating and/or Cd-tolerant plant systems (Huguet et al., 2015, 2012; Isaure et al., 2015). These pioneering studies demonstrated a change in Cd speciation upon Cd uptake through the roots, and during Cd translocation and storage in the leaves, and the involvement of thiols, organic acids and 65 phosphate ligands in response to Cd exposure (Huguet et al., 2012; Isaure et al., 2015, 2006). Recent progress in XAS spectroscopy triggered by the development of highly sensitive fluorescence detectors have opened the field of $\mathrm{Cd}$ speciation determination in 
plants with very low Cd concentrations such as cacao (Vanderschueren et al., 2020) or rice (Wiggenhauser et al., 2020) and have identified new Cd ligands like histidine (Vanderschueren et al., 2020), proving that XAS techniques still have a lot to offer to better characterize Cd behavior in the soil/plant system.

Here, we investigated $\mathrm{Cd}$ speciation in plants from the solanum family, $\mathrm{Cd}$ hyperaccumulator Solanum nigrum (S. nigrum; black nightshade) and non-tolerant (Sun et al., 2006) Solanum melongena (S. melongena; eggplant). Among the solanum family, several species are cultivated worldwide as food products - e.g. tomatoes, potatoes, bell peppers, eggplants, and have shown a tendency to Cd accumulation (e.g. eggplants, Sun et al., 2006; tomatoes, Hasan et al., 2019). Deciphering their responses to Cd exposure is of prime interest for food safety reasons. The mechanisms governing Cd distribution in these plants are still debated. Sun et al., (2006) study proposes that organic acids play a major role in solanum species behavior toward Cd (Li et al., 2020; Sun et al., 2006), as they found increasing carboxylic acid contents in S. nigrum and S. melongena leaves when exposed to high level of $\mathrm{Cd}$. By chemical titration, they reported organic acid over $\mathrm{Cd}$ ratios of $\sim 1000$ (Sun et al., 2006) and suggested that Cd accumulation and detoxification in these plants is regulated by complexation with organic acids alone. The involvement of organic acids in the handling of $\mathrm{Cd}$ has been invoked in other Solanaceae, such as tomato (Bao et al., 2011b). However, other studies reported, by chemical extraction and titration, an increase of thiol compounds - cysteine, glutathione and phytochelatins - in solanum plants exposed to Cd (Chamseddine et al., 2008; Gao et al., 2010; Hasan et al., 2019, 2015), including S. nigrum (Gao et al., 2010). In this context, this study aims at deciphering the fate of $\mathrm{Cd}$ in the solanum plants at the molecular level by performing, for the first time, Cd speciation characterization in Solanaceae using XAS spectroscopy. 


\section{Materials and methods}

\subsection{Plant and soil material}

500 seeds of Solanum nigrum - reference 'blackberry nightshade' - and Solanum melongena - reference 'black beauty eggplant' were purchased at a local gardening store. The soil used in this study is a clayey loam soil (LUFA Speyer standard 2.4, Table S1).

101 The soil was freshly field collected in a meadow with apple trees, then sieved at $2 \mathrm{~mm}$ and analyzed before shipment. Upon reception at the CEREGE, the soil was incubated with $103100 \mathrm{mg} \cdot \mathrm{kg}^{-1} \mathrm{Cd}$ as dissolved cadmium nitrate tetrahydrate (98\%, Sigma-Aldrich). Such 104 elevated Cd concentration, albeit $\sim 20$ times higher than reported values for $\mathrm{Cd}$ agricultural soils from the industrialized Chenzhou region in China (Robson et al., 2014; Wang et al., 2019; Zhai et al., 2008) and 200 times higher than the average Cd geochemical background in French soils (Baize, 1997), was chosen to ensure sufficient uptake of Cd by the plants prior to XAS analyses. We aimed at Cd content of $>50 \mu \mathrm{g} \cdot \mathrm{g}^{-1}$ dry weight in the plant parts, which was previously reported in S. nigrum and S. melongena grown on a 100 mg.kg ${ }^{-1}$ Cd-doped soil (Sun et al., 2006). The Cd-doped soil was brought to $70 \%$ of its maximum water holding capacity using deionized water, thoroughly mixed then stored for

1124 weeks in a growth chamber with controlled humidity, at a temperature of $24^{\circ} \mathrm{C}$. A control 113 soil was also prepared, without $\mathrm{Cd}$, but with the same amount of nitrate as dissolved $114 \mathrm{NaNO}_{3}$, following the same procedure.

\subsection{Plant cultures}

117 Solanum nigrum and S. melongena seeds were placed on some clean KimTech ${ }^{\text {TM }}$ wipes 118 soaked with deionized water, in Plexiglas boxes, at $28^{\circ} \mathrm{C}$ for 14 days, for germination. 119 Plastic gardening pots of $14 \mathrm{~cm}$ diameter were prepared with $2 \mathrm{~cm}$ of sand at the bottom 
and $\sim 500 \mathrm{~g}$ of incubated Cd-doped or control soil in each pot. Two-week-old seedlings of

121 S. nigrum and $S$. melongena with shoots of about $2 \mathrm{~cm}$ were then transplanted into the

122 pots (2 seedlings per pot). Six pots per plant type were prepared for the Cd-doped soil and

123 for the control soil. Plants were cultivated in a controlled growth chamber with fixed

124 temperature of $24^{\circ} \mathrm{C}$, controlled humidity, and photoperiod (light: 6 am $-9 \mathrm{pm}$ ). Each pot 125 was automatically watered individually with deionized water, twice a day (at 9 am and 5 $126 \mathrm{pm})$, to maintain the soil at $70 \%$ of its maximum water holding capacity. No fertilizer was 127 added. The plants where harvested after a growth period of 14 weeks. For each plant type 128 and soil treatment, four replicates were used for total $\mathrm{Cd}$ content analyses and 3 replicates 129 were prepared for XAS measurements, following two protocols detailed in the next two 130 paragraphs.

\subsection{Analysis of total $\mathrm{Cd}$ content in the plant parts (exposed and control samples)}

After harvest, roots and aerial parts have been separated at the collar level and cleaned with ultrapure water $(18.2 \mathrm{M} \Omega \cdot \mathrm{cm})$. Roots received additional cleaning by gentle brushing and vortexing in water. Fresh leaves and stems were separated. Plant samples were dried in an oven set at $40^{\circ} \mathrm{C}$ during $48 \mathrm{~h}$. Roots, stems and fresh leaves were weighed before

137 (fresh weight) and after drying (dry weight; Tables S6 and S7). Plant samples (roots, fresh 138 leaves, stems) were ground for $2 \mathrm{~min}$ at $20 \mathrm{hz}$ with a Retsch $\AA$ Mixer Mill MM 400 to obtain a 139 fine powder. 100 to $300 \mathrm{mg}$ of each plant sample was then digested in a mixture of nitric 140 acid, hydrochloric acid and peroxide using a microwave (MLS turboWAVE®). Total 141 cadmium analyses were performed on the Q-ICPMS (quadrupole-inductively coupled 142 plasma mass spectrometer, Perkin Elmer Nexlon 300X). 
Plants and soils preparation for XAS measurements. After Cd incubation, and prior to the pot experiments, $\sim 50 \mathrm{~g}$ of soil was frozen in a $-80^{\circ} \mathrm{C}$ freezer to avoid changes in speciation. This initial soil will be referred as 'pre-culture soil to'. After 14 weeks of pot

experiments, S. nigrum and S. melongena samples were carefully harvested and cleaned.

Roots received additional cleaning by gentle brushing and vortexing in water. Special attention was paid to ensure that no soil residue would remain on any parts of the plants, especially on the roots of both $S$. nigrum and $S$. melongena and on the dead leaves of $S$. melongena, to prevent soil Cd contamination of the plant tissues. For XAS measurements, S. nigrum plants were cut and divided into: roots, top fresh leaves, bottom fresh leaves, and stem. Solanum melongena plants were cut and divided into: roots, fresh leaves, stem and dead leaves (detached from the plant). All plant parts were weighed then directly frozen in liquid nitrogen and stored in a $-80^{\circ} \mathrm{C}$ freezer, to prevent any speciation change before the synchrotron measurements. All further preparation steps were performed frozen, using liquid nitrogen. Cryogenic grinding was performed on all plant and soil samples using zirconium oxide beads in $2 \mathrm{~mL}$ Eppendorf tubes with a Retsch® Mixer Mill MM 400. $7 \mathrm{~mm}$ diameter pellets were then prepared using a hand press with dies cooled in

161 liquid nitrogen. Samples were transported to the Diamond Light Source and to Soleil Synchrotron on dry ice.

Cd reference compounds. A large database of Cd-containing reference compounds was analyzed for X-ray Absorption Near Edge Structure (XANES) and Extended X-ray Absorption Fine Structure (EXAFS) to allow the interpretation of XAS spectra obtained on

167 the soil and plant natural samples (Huguet et al., 2015, 2012; Isaure et al., 2015;

168 Vanderschueren et al., 2020). Some of these Cd reference materials were purchased 169 chemicals, the others were prepared at the laboratory. Commercial $\mathrm{Cd}$ minerals included $170 \mathrm{CdS}, \mathrm{Cd}(\mathrm{OH})_{2}, \mathrm{CdO}, \mathrm{CdCl}_{2}, \mathrm{CdPO}_{4}, \mathrm{CdCO}_{3}$ and $\mathrm{CdSO}_{4}$. A solution of aqueous $\mathrm{Cd}^{2+}$ 
$171\left(\mathrm{Cd}\left(\mathrm{H}_{2} \mathrm{O}\right)_{6}{ }^{2+}\right)$ reference was prepared by dissolving commercial $\mathrm{Cd}(\mathrm{NO} 3)_{2}\left(\mathrm{H}_{2} \mathrm{O}\right)_{4}$ in Milli-Q

172 water. A library of Cd-organic complexes, composed of several $\mathrm{Cd}$ bound to organic acids 173 relevant to the solanum species (Sun et al., 2006) - Cd-acetate, Cd-malate, Cd-citrate, 174 Cd-tartrate, Cd-phytate - as well as thiol Cd compounds - Cd-glutathione, Cd-cysteine 175 and amino acid Cd-histidine, were synthetized in the laboratory (Supplementary Material 176 Part 1). To better constrain Cd speciation in the soil, we also analyzed a synthetic Cd177 sorbed goethite (Hammer et al., 2006) and a naturally Cd-rich calcite collected at Dornach 178 (NW Switzerland). The compounds $\mathrm{CdS}, \mathrm{Cd}(\mathrm{OH})_{2}, \mathrm{CdO}$ and $\mathrm{CdSO}_{4}$ were prepared as 179 pressed pellets diluted with PVP, while all other references were prepared as liquid 180 solutions. Prior to XAS measurements, pellets or liquid references were frozen in liquid 181 nitrogen. Spectra for all Cd-containing pellet references and $\mathrm{Cd}$ glutathione, $\mathrm{Cd}$ 182 phosphate, $\mathrm{Cd}$ acetate and $\mathrm{Cd}\left(\mathrm{H}_{2} \mathrm{O}\right)_{6}{ }^{2+}$ solutions were recorded at $\mathrm{Cd} \mathrm{K}$-edge in 183 transmission mode. Other liquid references were measured at $\mathrm{Cd} \mathrm{K}$-edge in fluorescence 184 mode. The Cd K-edge EXAFS spectra of all Cd reference compounds and their Fourier 185 transforms are presented in Figure S2. The Cd K-edge XANES spectra of all Cd reference 186 compounds are presented in Figure S3.

188 Cd K-edge XANES and EXAFS Spectroscopy. Cd K-edge (E0=26711 eV) XANES and 189 EXAFS experiments were performed during two synchrotron facility sessions carried out at 190 the Diamond Light Source (Didcot, United Kingdom) and at the SOLEIL synchrotron facility 191 (Saint-Aubin, France). At the Diamond Light Source, the experiments were performed on 192 the B18 core XAS beamline (for more information on the beamline, see the supplementary 193 materials, part 2), which is equipped with a Si (311) monochromator for measurements at 194 high energy (>20 keV). The storage ring was operated at $3 \mathrm{GeV}$ with a ring current of 300 195 mA. Samples were measured using a 35-element germanium Solid State Detector (SSD) 196 in fluorescence detection mode. X-ray absorption spectra were scanned from $26523 \mathrm{eV}$ to 
$27093 \mathrm{eV}$ for the diluted samples and from $26523 \mathrm{eV}$ to $27711 \mathrm{eV}$ for the references in quick EXAFS mode ( 4 min per spectrum). For each sample, 100 to 180 spectra were acquired, aligned, and merged. The energy calibration was performed using a Cd foil sheet. The beam spot size was set to $1.5 \times 1.5 \mathrm{~mm}$. To avoid Cd speciation change during measurements, the sample pellets and liquid references were measured using a liquid nitrogen Oxford Optistat cryostat set at 93K. At the Soleil Synchrotron, the experiments were performed on the SAMBA beamline (for more information on the beamline, see the supplementary materials, part 2), which is equipped with a Si (220) monochromator for measurements at high energy (>20 keV). The storage ring was operated at $2.75 \mathrm{GeV}$ with a ring current of $500 \mathrm{~mA}$. Samples were measured using a 35-element germanium SSD in fluorescence detection mode. X-ray absorption spectra were scanned from 26523 eV to $27093 \mathrm{eV}$ for the diluted samples and from $26523 \mathrm{eV}$ to $27711 \mathrm{eV}$ for the references in quick EXAFS mode ( 3 min per spectrum). For each sample, 50 to 110 spectra were acquired, aligned, and merged. The energy calibration was performed using a Cd foil sheet. The beam spot size was set to $2 \times 0.5 \mathrm{~mm}$. All samples and references were 212 measured using a liquid nitrogen cryostat set at $80 \mathrm{~K}$.

213 For all samples, the extracted EXAFS spectra were $\mathrm{k}^{2}$ weighted (with $\mathrm{k}$ : wave vector) to 214 enhance the high-k region. Data treatment was performed using the ATHENA (Ravel and 215 Newville, 2005), ARTEMIS (Ravel and Newville, 2005) and FASTOSH (Landrot, 2018) 216 softwares. Fourier transforms were performed of the $k$ range from 2 to $9 \AA^{-1}$ to $R$ space 217 using a Hanning apodization window. The structural and chemical parameters of the 218 references (Table S3) and of the soil samples (Table S10) were modelled by shell-by-shell 219 fitting using the ARTEMIS software. Shell-fitting analysis of the $\mathrm{k}^{2}$-weighted EXAFS 220 spectra was performed in R-space. Theoretical EXAFS phase-shift and amplitude 221 functions for the paths were calculated using FEFF (Rehr et al., 2010). Principal 222 component analyses (PCA) were performed on the soil samples and on the plant samples 
223 to determine the number of references needed to explain our datasets. PCA were the

224 FASTOSH software (Landrot, 2018). Target transform were performed on every single Cd 225 reference compound to assess whether they constitute good candidates to explain $\mathrm{Cd}$ 226 speciation in our soil/plant system (Wasserman, 1997; Wasserman et al., 1999). The best 227 linear combination fitting (LCF) of our samples EXAFS spectra were determined using the 228 LCF fitting module of the FASTOSH software over the $k$ range 2 to $9 \AA^{-1}$ with a fixed $E_{0}$ 229 value of $26710.4 \mathrm{eV}$. Residual factor of LCF was calculated using the following equation:

$$
\mathrm{R}=\Sigma\left(k^{2} \chi(k)_{\text {exp }}-k^{2} \chi(k)_{f i t}\right)^{2} / \Sigma\left(k^{2} \chi(k)_{\text {exp }}\right)^{2}
$$

231 At each step of the fitting, an additional reference spectrum was added if the two following 232 conditions were true: the $\mathrm{R}$ factor decreased by $20 \%$ or more and the additional reference 233 had a contribution equal to or higher than 10\% among Cd-species. For the same number 234 of references, two different LCF fittings are considered undistinguishable if their R factor is 235 comprised within $20 \%$. The uncertainty of this LCF method was estimated at $+/-15 \%$ 236 (Doelsch et al., 2006; Le Bars et al., 2018). PCA, target transforms and LCF fittings are further discussed in the results part and in the supplementary material (Part 3).

\section{Results and discussion}

\subsection{Plant Cd content and aspect}

242 Solanum nigrum has been identified as a potential Cd-hyperaccumulator plant (Sun et al., 243 2006; Wei et al., 2005). The definition of hyperaccumulation depends on the considered 244 metal. For Cd, several studies have proposed to define Cd hyperaccumulation ability as 245 the accumulation of $\mathrm{Cd}$ in the stems or leaves of the plant exceeding the threshold of 100 $246 \mu \mathrm{g} . \mathrm{g}^{-1}$, dry weight (Baker et al., 2000; Huguet et al., 2015; Isaure et al., 2015; Lu et al., 247 2013; Sun et al., 2011, 2006; Uraguchi et al., 2006; Wei et al., 2005). In our experiments, 
S. nigrum leaves show average values of $126.5 \pm 12 \mu \mathrm{g} \cdot \mathrm{g}^{-1} \mathrm{Cd}$ in leaves (DW, Table 1). $60 \%$ of $S$. nigrum total $\mathrm{Cd}$ content is located in its shoots $16 \%$ in the stem, $54 \%$ in the leaves, Table 1). In Sun et al., 2006, S. melongena has been described as 'less tolerant' towards Cd than S.

nigrum. For S. melongena plants grown on a $100 \mathrm{mg} \cdot \mathrm{kg}^{-1} \mathrm{Cd}$ doped soil, they report Cd concentrations of $64 \mu \mathrm{g} \cdot \mathrm{g}^{-1}$ (DW) in leaves and $189 \mu \mathrm{g} \cdot \mathrm{g}^{-1}$ (DW) in roots. Our results are consistent with these values, with Cd concentrations of $59 \mu \mathrm{g} \cdot \mathrm{g}^{-1}$ (DW) in leaves and 244 $\mu \mathrm{g} \cdot \mathrm{g}^{-1}$ (DW) in roots (Table 1). While $S$. melongena does not fit the definition of Cdhyperaccumulation, S. melongena does accumulate a significant amount of $\mathrm{Cd}$ when exposed to this metal. Our results show that $S$. nigrum display enhanced capacity to accumulate $\mathrm{Cd}$ in its aerial parts $(60 \%$ total $\mathrm{Cd}$ in stem + leaves) compared to $S$. melongena (41\%, Table 1$)$, with a slightly higher roots to aerial parts $\mathrm{Cd}$ translocation factor $(0.31$ for $S$. nigrum and 0.24 for $S$. melongena; a Student t-test identifies the two groups as distinct at a 93.7\% confidence interval; Table S7).

Solanum nigrum plants grown on the Cd-doped soil show signs of leaf chlorosis in the 264 older, bottom leaves (Figure S4), as well as significantly (Student t-test, 95\% C.I.) lower 265 roots, stem and leaves biomass compared to plants grown on the control soil (Figure 1, 266 Figure S5 and Table S6 and S7). Solanum melongena plants grown on $100 \mathrm{mg} \cdot \mathrm{kg}^{-1} \mathrm{Cd}_{-}$ 267 doped soil have roots that display more friable texture than that of the control plants. No $S$. 268 melongena plants from the $\mathrm{Cd}$ doped experiment reached a stage where more than two 269 leaves were present at the same time, while $S$. nigrum plants reached a more mature 270 stage (up to 10 leaves). Solanum melongena plants exposed to Cd also show significantly 271 (Student t-test, 95\% C.I.) lower roots biomass, and a tendency to lower stem and leaves 272 biomass compared to the control plants (Figure 1 and Table S6 and S7). For both $S$. 273 nigrum and S. melongena, all of the above constitute well-described consequences of 
exposure to high levels of Cd (Das et al., 1997; Maqbool et al., 2019; Prasad, 1995;

275 Rizwan et al., 2012).

Table 1: Cd average concentrations, dry weights, and total $\mathrm{Cd}$ contents measured in S. nigrum and S. melongena grown

\begin{tabular}{|c|c|c|c|c|c|c|c|c|}
\hline & & & & & & \multirow{3}{*}{$n$} & \multirow{3}{*}{$\begin{array}{l}\text { Cd }(\mu \mathrm{g}) \\
\text { Average } \\
\text { total Cd } \\
\text { content }\end{array}$} & \multirow{3}{*}{$\begin{array}{c}\text { Cd (\%) } \\
\text { Average } \\
\text { total Cd } \\
\text { content }\end{array}$} \\
\hline & \multirow{2}{*}{$\begin{array}{c}\mathrm{Cd}\left(\mu \mathrm{g} \cdot \mathrm{g}^{-1}\right) \\
\text { measured on } \\
\text { dry sample }( \pm \\
1 \text { s.d.) }\end{array}$} & \multirow{2}{*}{\multicolumn{2}{|c|}{\begin{tabular}{|c|} 
DW $(\mathrm{mg})$ \\
$\begin{array}{c}\text { Dry weight } \\
\text { ( } \pm 1 \text { s.d.) }\end{array}$
\end{tabular}}} & & & \\
\hline plant type & $\begin{array}{c}\text { soil Cd } \\
\text { concentration }\end{array}$ & $\begin{array}{c}\text { Plant } \\
\text { Part }\end{array}$ & & & & & & \\
\hline \multirow[t]{3}{*}{ S. melongena } & $100 \mathrm{mg} \cdot \mathrm{kg}^{-1}$ & Roots & $243.8 \pm 9$ & 4 & $39.8 \pm 10$ & 4 & 9.7 & 59 \\
\hline & & Stem & $58.5 \pm 10$ & 4 & $28.9 \pm 4$ & 4 & 1.7 & 10 \\
\hline & & $\begin{array}{l}\text { Fresh } \\
\text { leaves }\end{array}$ & $58.8 \pm 10$ & 4 & $87.1 \pm 38$ & 4 & 5.2 & 31 \\
\hline \multirow[t]{3}{*}{ S. nigrum } & $100 \mathrm{mg} \cdot \mathrm{kg}^{-1}$ & Roots & $376.8 \pm 87$ & 4 & $33.6 \pm 17$ & 4 & 12.5 & 40 \\
\hline & & Stem & $43.8 \pm 6$ & 4 & $41.4 \pm 26$ & 4 & 1.8 & 6 \\
\hline & & $\begin{array}{l}\text { Fresh } \\
\text { leaves }\end{array}$ & $126.5 \pm 12$ & 4 & $130.8 \pm 40$ & 4 & 16.7 & 54 \\
\hline
\end{tabular}

\subsection{No change in soil Cd speciation upon plant culture}

285 Cadmium speciation in the $100 \mathrm{mg} \cdot \mathrm{kg}^{-1} \mathrm{Cd}$ doped soil before and after culture of both

Solanum nigrum and S. melongena was assessed by EXAFS spectroscopy. Principal component analysis (PCA) performed on EXAFS spectra of six soil samples identified up

to two components (Supplementary material Part 3), meaning one to two Cd reference

289 compounds are needed to reconstruct soil samples EXAFS spectra through linear combination fitting (LCF). XAS spectra of pre- and post-culture soils for both S. nigrum and S. melongena are visually almost identical (Figure S6). They are also very similar to the spectrum of the Cd-sorbed artificial goethite we measured (Figure S6). Sorption of Cd onto oxides and hydroxides in soils is a known mechanism that has been documented in

294 several studies, for example Cd sorption on manganese oxyhydroxides (Chen et al., 2019; 
295 Kubier et al., 2019; Lin et al., 2016; Wasylenki et al., 2014) or iron oxyhydroxides, 296 including goethite (Barrow et al., 1989; Bruemmer et al., 1988; Gerth et al., 1993; Gerth 297 and Bruemmer, 1983). However, due to the low amount of $\mathrm{Cd}$ in the goethite reference 298 ( 50 mg. $\mathrm{kg}^{-1} \mathrm{Cd}$ ), the Cd-sorbed goethite EXAFS spectrum presents significant noise in 299 the high $\mathrm{k}$ region. For these reasons, we chose to use the XANES part of our soil samples 300 spectrum (from $-30 \mathrm{eV}$ to $+100 \mathrm{eV}$ ) to perform linear combination fittings. Figure 2 shows 301 our soil samples XANES spectra and their best fit, along with Cd-sorbed goethite, Cd302 phytate and $\mathrm{Cd}$-organic acids reference spectra. In the pre-culture, $100 \mathrm{mg} \cdot \mathrm{kg}^{-1} \mathrm{Cd}$-doped 303 soil, the spectrum was best reconstructed with 100\% Cd-sorbed goethite (Figure 3; 304 Supplementary Table S9). Post-culture S. nigrum soil XANES LCF fit gives the same 305 result: $100 \%$ Cd sorbed onto goethite. For S. melongena post-culture soil, our fitting 306 method suggests a contribution of Cd bound to organic acids, with the best LCF fits giving $30785 \%$ Cd sorbed to goethite and $15 \%$ Cd bound to acetate. Our LCF method also gave 308 acceptable results for citrate, malate and tartrate as oxygen ligand candidates. The 309 secretion of organic acids in roots exudates is a well-documented phenomenon (Adeleke 310 et al., 2017; Bao et al., 2011b; Han et al., 2006; Loganathan et al., 2012). In various plant 311 families, including solanum plants, the root exudation of organic acids enhances the 312 bioavailability of nutrient metals such as zinc or iron in soils (Bao et al., 2011a; 313 Samardjieva et al., 2015). Cadmium is a non-essential cation with similar properties as 314 zinc. The release of organic acids by $S$. melongena roots in the soil might consequently 315 cause partial $\mathrm{Cd}$ desorption from oxyhydroxides and enhance $\mathrm{Cd}$ phytoavailability. 316 Changes in soil Cd speciation from Cd mineral species to Cd bound to organic acids after 317 plant culture has been previously identified by Huguet et al (Huguet et al., 2015). Overall, 318 considering our LCF method gives an uncertainty of $+/-15 \%$ on the percentage of $\mathrm{Cd}$ 319 species, our results for pre- and post-culture soils, regardless of the plant type, are quite 320 similar. This is consistent with the structural and chemical parameters we obtained by 
321 performing a first shell fit of our soil samples Cd k-edge EXAFS spectra using the ARTEMIS software (Ravel and Newville, 2005). All three samples show the same Cd coordination to $\mathrm{O}$ atoms $(\mathrm{N} \sim 5.6)$ with $\mathrm{Cd}-\mathrm{O}$ bond length of $2.26 \AA$ (see Supplementary Table S10), which is also very close to the structural parameters modelled for the $\mathrm{Cd}$ sorbed goethite reference (backscatterer in the first coordination sphere: $\mathrm{O} ; \mathrm{N}=5.7, \mathrm{Cd}-\mathrm{O}$ $R=2.25 \AA)$. We interpret this overall lack of differences in Cd speciation in soil before and after culture as the expression of a mass balance effect. The total $\mathrm{Cd}$ content in $S$. melongena and S. nigrum is $\sim 30 \mu \mathrm{g}$ (Table 1). Considering two plants per pot, the plants have taken up $60 \mu \mathrm{g}$ of $\mathrm{Cd}$ per pot, which represents $0.12 \%$ of the initial $\mathrm{Cd}$ content. Despite the roots of both plants having colonized the whole pot, the bulk $500 \mathrm{~g}, 100 \mathrm{mg} \cdot \mathrm{kg}^{-}$ ${ }^{1}$ Cd-doped soil is not significantly affected by the plants.

\subsection{Cd speciation in S. nigrum and S. melongena}

Cd k-edge EXAFS spectra of plant parts and corresponding Fourier transforms are presented in figure 4. Linear combination fitting (LCF) of S. nigrum and S. melongena plant parts EXAFS spectra (from $k=2$ to $k=9$ ) were performed using the EXAFS spectra of all of the $\mathrm{Cd}$ reference compounds measured in this study. The best linear combination fittings of samples EXAFS spectra and associated Fourier transforms are also plotted in Figure 4

340 (for LCF numerical result, see Table S11). In our plant samples, the fitting of EXAFS 341 spectra allowed us to identify the first neighbor of $\mathrm{Cd}$ as oxygen or sulfur. As detailed in 342 the following paragraphs, potential -O ligands included organic acids, histidine, phytate or $343 \mathrm{Cd}\left(\mathrm{H}_{2} \mathrm{O}\right)_{6}{ }^{2+}$. Potential -S ligands included binding to mineral sulfur (CdS) and organic sulfur 344 as glutathione or cysteine. Obtained proportion of $\mathrm{Cd}-\mathrm{O}$ and $\mathrm{Cd}-\mathrm{S}$ species for best EXAFS 345 LCF fits are displayed in Figure 5. Cd k-edge XANES spectra of the plant samples are 346 presented in Figure S7. Linear combination fitting of S. nigrum and S. melongena plant 
parts XANES spectra (from 26680 to $26810 \mathrm{eV}$ ) were performed using the XANES spectra of all of the Cd reference compounds measured in this study (displayed in Figure S3). The best linear combination fittings of samples XANES spectra are also plotted in Figure S7 (for LCF numerical result, see Table S11). Obtained proportion of Cd-O and Cd-S species for best XANES LCF fits are displayed in Figure S8, alongside best EXAFS LCF fits for comparison. As demonstrated by Figure S8 and LCF results in Table S11, both EXAFS and XANES analyses give the same results. For this reason, we chose to use the EXAFS data analyses for the plant samples.

A change of $\mathbf{C d}$ speciation upon plant uptake in the roots. Our results show that the main first neighbor of $\mathrm{Cd}$ in both $S$. nigrum and $S$. melongena roots is sulfur $(77 \%$ and $100 \%$ respectively, Figures 4 and 5). In S. nigrum roots, the remaining $\mathrm{Cd}$ is bound to oxygen. All the acceptable linear combination fittings involve the Cd-glutathione model compound, a thiol molecule, as the S-bearing ligand (Supplementary material Part 1). For the oxygen counterpart in $S$. nigrum, while the best residue (R factor) was obtained with Cd-tartrate, the LCF method could not distinguish between $\mathrm{Cd}\left(\mathrm{H}_{2} \mathrm{O}\right)_{6}{ }^{2+}$, Cd-histidine, or any of the Cd-organic acids analyzed (malate, tartrate, citrate, and acetate).

364 These results first demonstrate a major change of $\mathrm{Cd}$ speciation between the soil (Cd sorbed to goethite) and the roots (Cd mainly bound to organic -S) for both solanum species. From our results alone, it is unclear how the $\mathrm{Cd}$ sorbed to goethite in the soil becomes available to the plants. Several studies suggest that plants can participate in the release and dissolution of $\mathrm{Cd}$ sorbed onto oxyhydroxides, as root exudation of organic acids - particularly tartrate and acetate - is involved in heavy metal uptake by roots (Bao et al., 2011b; Fan et al., 1997; Sun et al., 2006). The Cd in S. melongena and S. nigrum roots is then mainly complexed with thiol ligands (100\% for $S$. melongena and $77 \%$ for $S$. nigrum). In S. melongena, most of the $\mathrm{Cd}$ is located in the roots (Table 1), that show $\mathrm{Cd}$ 
concentration of $\sim 5$ times that of the stem and fresh leaves (Table 1 ) and a roots to aerial parts translocation factor of $\sim 0.24$. In non-accumulator plants, Cd binding to thiols and vacuolar sequestration of these complexes has been previously described as a detoxification mechanism (Cobbett, 2000; Marentes and Rauser, 2007; Mendoza-Cózatl et al., 2008; Pál et al., 2018; Uraguchi and Fujiwara, 2012; Wawrzyński et al., 2006), with possible storage of these complexes in the roots (Cao et al., 2018; Nocito et al., 2011; Rauser, 2003; Salt et al., 2002, 1995; Ueno et al., 2010; Wiggenhauser et al., 2020). The binding of $\mathrm{Cd}$ to non-chelating thiols such as glutathione and cysteine or to chelating thiols such as phytochelatins in the roots could immobilize $\mathrm{Cd}$ and prevent its translocation to the aerial parts of the plant (Cao et al., 2018; Nocito et al., 2011; Salt et al., 2002). In rice, a recent XAS study by Wiggenhauser and collaborators (Wiggenhauser et al., 2020) demonstrated that $\mathrm{Cd}$ in roots is $100 \%$ bound to $\mathrm{S}$ ligands, bringing new, direct evidence of the role of $\mathrm{Cd}$ binding to $\mathrm{S}$ in $\mathrm{Cd}$ sequestration in roots and echoing our findings. We therefore conclude that $\mathrm{Cd}$ bound to organic $-\mathrm{S}$ ligands in $\mathrm{S}$. melongena roots constitutes a storage form that limits $\mathrm{Cd}$ translocation to aerial parts and participates in its detoxification. In the Cd-hyperaccumulator S. nigrum, most of the $\mathrm{Cd}$ is bound to $\mathrm{S}$ ligands $(77 \%)$ and the $\mathrm{Cd}$ translocation factor from roots to aerial parts is 0.31 . Like $S$. melongena, we suggest that $\mathrm{Cd}$ in roots is mainly immobilized and stored as Cd-thiol complexes. Such mechanism has also been suggested in the Cd-hyperaccumulator Brassica juncea $L$. for which $\mathrm{Cd}$ coordination with S was demonstrated using XAS spectroscopy (Salt et al., 1995). For the remaining $23 \%$ of $\mathrm{Cd}$ bound to oxygen in S. nigrum roots, we considered two scenarios: (i) this $\mathrm{Cd}-\mathrm{O}$ fraction is also a storage form or (ii) it represents a transient fraction that could be translocated to the aerial parts. (i) Storage of $\mathrm{Cd}$ as $\mathrm{Cd}-\mathrm{O}$ has been previously reported in Cd-hyperaccumulator plants. In the Cd-hyperaccumulator plant Thlaspi praecox, a Brassicaceae that can accumulate very high amount of $\mathrm{Cd}$ in its shoot $\left(>7500 \mu \mathrm{g} \cdot \mathrm{g}^{-1}\right.$, DW, Lombi et al., 2000; Vogel-Mikuš et al., 2006), Vogel-Mikuš and her collaborators performed 
XAS measurements and reported that, of the $858 \mu \mathrm{g} \cdot \mathrm{g}^{-1}$ (DW) Cd in T. praecox roots, $79 \%$ was bound to $-\mathrm{O}$ ligands (as $\mathrm{Cd}-\mathrm{O}-\mathrm{C}$ ), and the remaining $21 \%$ was bound to $-\mathrm{S}$ ligands (as thiols, Vogel-Mikuš et al., 2010). They suggest that $\mathrm{Cd}$ is mainly bound to cell-wall -O ligand components or stored in the vacuoles, complexed with organic acids. Organic acid vacuolar sequestration of cadmium, albeit limited in the roots compared to the shoots, is a well-described detoxification mechanism in Cd hyperaccumulator plants (Han et al., 2006; Huguet et al., 2012; Isaure et al., 2015; Küpper et al., 2004; Lombi et al., 2000; Maqbool et al., 2019; Sun et al., 2011; Vogel-Mikuš et al., 2010). We cannot rule out that such mechanism takes place in $S$. nigrum roots and account for part of the Cd-O we reported. (ii) However, given that $\mathrm{Cd}$ speciation in S. nigrum stem shows an increase in Cd binding to $\mathrm{O}$ ligands (55\%, Figure 5 ) for an amount of $\sim 3.3 \%$ of the plant total $\mathrm{Cd}$ (Table 1 ), we consider that the $\mathrm{Cd}$ bound to $\mathrm{O}$ in the roots ( $\sim 9.2 \%$ of the plant total $\mathrm{Cd})$ could be a $\mathrm{Cd}$ transient form for roots to aerial parts translocation. This $\mathrm{Cd}$ transport form hypothesis will be further discussed in the next paragraph on Cd speciation in the stems.

Cadmium transport forms in $S$. nigrum and $S$. melongena stems. The linear combination fittings of stem EXAFS spectra show contrasting results for $S$. nigrum and $S$. melongena, as the main first neighbor of $\mathrm{Cd}$ for $\mathrm{S}$. nigrum is $\mathrm{O}(55 \% \mathrm{O}, 45 \% \mathrm{~S}$, Figure 5$)$ while it is $\mathrm{S}$ for $\mathrm{S}$. melongena $(78 \% \mathrm{~S}, 22 \% \mathrm{O}$, Figure 5). For S. nigrum, the best LCF fittings involve non-protein thiol glutathione as the S-bearing ligand. For the $\mathrm{O}$ ligand in $S$. nigrum, the best fit is obtained with acetate, but other organic acids malate, citrate, and tartrate, as well as $\mathrm{Cd}\left(\mathrm{H}_{2} \mathrm{O}\right)_{6}{ }^{2+}$, histidine, give acceptable results according to our LCF method. As for $S$. melongena, all the best LCF give glutathione as the $S$ bearing ligand, and tartrate as the best $\mathrm{O}$ ligand. Other organic acids, $\mathrm{Cd}\left(\mathrm{H}_{2} \mathrm{O}\right)_{6}{ }^{2+}$, histidine and phosphate also give acceptable results. 
S. melongena stem and fresh leaves display very similar cadmium concentrations ( 58 $\mu \mathrm{g} \cdot \mathrm{g}^{-1} \mathrm{DW}$, Table 1$)$, much lower than that of the roots $\left(\sim 250 \mu \mathrm{g} \cdot \mathrm{g}^{-1} \mathrm{DW}\right)$. Compared to $S$. nigrum, for which fresh leaves $\mathrm{Cd}$ concentration is three times higher than in stem $(\sim 127$ and $\sim 44 \mu \mathrm{g} \cdot \mathrm{g}^{-1} \mathrm{DW}$ respectively, Table 1 ), our results point towards a more limited translocation of $\mathrm{Cd}$ in $S$. melongena stem. Previous studies demonstrated - using XAS spectroscopy(Salt et al., 2002, 1995) - or suggested (using chemical titration, MendozaCózatl et al., 2008) that Cd can be transported in the xylem sap bound to oxygen bearing components. Our EXAFS measurements show that the binding of $\mathrm{Cd}$ to $\mathrm{O}$ ligands in $S$. melongena is restricted to the stem, which we interpret as $\mathrm{Cd}$ transportation form in the saps. In S. nigrum, Cd concentration and contents in the plant parts (Table 1) indicate a more intense translocation of $\mathrm{Cd}$ from the roots to the leaves, where $\mathrm{Cd}$ is stored. As mentioned earlier, the amount of $\mathrm{Cd}$ bound to oxygen ligands in the stem $(55 \%$ of stem $\mathrm{Cd} ; 3.3 \%$ of the plant total $\mathrm{Cd})$ is close to that of the roots $(\sim 9.2 \%$ total $\mathrm{Cd})$. This value is also similar to the one in S. nigrum fresh top leaves $(15 \% \mathrm{Cd}-\mathrm{O}$ in the leaves; $8.1 \%$ of the plant total Cd, Figure 5). We interpret these results as an argument in favor of $\mathrm{Cd}-\mathrm{O}$ being the translocation form for Cd in S. nigrum.

440 Like $S$. melongena, we propose that the prevalence of $O$ ligands in the stem of $S$. nigrum 441 is to be attributed to the transport form of $\mathrm{Cd}$ in the xylem sap. Our results suggest that $\mathrm{Cd}$ 442 is transported bound to $O$ ligands, unlike what was observed in Arabidopsis halleri and $A$. lyrata (Isaure et al., 2015) or Cd-hyperaccumulator Noccaea caerulescens (Küpper et al., 444 2004), where $\mathrm{Cd}$ is associated with glutathione. The possible transportation of $\mathrm{Cd}$ as $445 \mathrm{Cd}\left(\mathrm{H}_{2} \mathrm{O}\right)_{6}{ }^{2+}$ in the xylem sap of $A$. halleri has been proposed by Ueno et al., 2008 (Ueno et 446 al., 2008). In Brassica napus, Mendoza-Cózatl et al. (2008) suggested that Cd in xylem 447 sap could also be complexed by oxygen ligands. As for the specific $O$ ligands candidates, 448 histidine has been reported for zinc transport in sap (Küpper et al., 2004), and 449 complexation of $\mathrm{Zn}$ by organic acids has been invoked in $A$. halleri xylem sap (Cornu et al., 
450

2015). Given that Cd is considered Zn sister element, and that Sun et al 2006 (Sun et al., 2006) identified increased amount of organic acids in S. nigrum when exposed to $\mathrm{Cd}$, we hypothesize that $\mathrm{Cd}$ could be transported bound to organic acids in S. nigrum xylem sap, though further investigation is needed to rule out the involvement of histidine or $\mathrm{Cd}\left(\mathrm{H}_{2} \mathrm{O}\right)_{6}{ }^{2+}$. As for the phloem, Mendoza-Cózatl $(2011,2008)$ suggested transport of $\mathrm{Cd}$ by non-protein thiol compounds, namely glutathione, and possibly phytochelatins, in Brassica napus. This could explain the ligand mixture we measured in S. nigrum stem, with $\mathrm{Cd}$ being complexed with $\mathrm{O}$ ligands in the xylem sap and with $\mathrm{S}$ ligands in the phloem sap (Figure 5).

Storage of S-bound $\mathbf{C d}$ in S. nigrum and S. melongena leaves. Our results show that the main first neighbor of $\mathrm{Cd}$ in both $\mathrm{S}$. nigrum and $\mathrm{S}$. melongena fresh leaves is sulfur (Figure 5). In S. melongena fresh leaves, $100 \%$ of $\mathrm{Cd}$ is bound to organic sulfur ligands (glutathione, Figures 4 and 5). In S. nigrum, Cd speciation depends on the leaf maturity. Younger, top leaves EXAFS spectrum is best reproduced with three components: $\mathrm{Cd}$ bound to organic sulfur (best fit with glutathione, 58.4\%), Cd bound to inorganic sulfur (best fit with CdS, 27.1\%) and Cd bound to oxygen ligands (best fit: 14.5\% -O). While the best LCF fit involves $\mathrm{Cd}$ bound to tartrate, the method gives acceptable results for $\mathrm{Cd}$ histidine, $\mathrm{Cd}\left(\mathrm{H}_{2} \mathrm{O}\right)_{6}{ }^{2+}$ and the other organic acids measured. In $\mathrm{S}$. nigrum, older, bottom leaves, we found that $100 \%$ of $\mathrm{Cd}$ is bound to sulfur ligands: $74.4 \%$ to organic sulfur ligands (Cd-glutathione) and $25.6 \%$ to inorganic sulfur (CdS). For both S. nigrum and $S$. melongena, our results do not validate Sun et al., 2006 hypothesis that, for plants grown in the same conditions, Cd could be entirely complexed by organic acids in their leaves (Sun et al., 2006), as they reported high amounts of tartrate and acetate in leaves of $S$. melongena and of malate in leaves of $S$. nigrum. 
477 Cd in S. melongena leaves.

478 Previous EXAFS studies performed on leaves from Cd-hyperaccumulators T. praecox 479 (Vogel-Mikuš et al., 2010) and Arabidospsis halleri (Huguet et al., 2012; Isaure et al., 4802015 ) or Cd-tolerant Arabidopsis halleri x A. lyrata progenies (Isaure et al., 2015) plants 481 demonstrated that $\mathrm{Cd}$ is mainly bound to $-\mathrm{O}$ ligands, and that $\mathrm{S}$ ligands are secondary 482 species. They link complexation of $\mathrm{Cd}$ to oxygen ligands to the plant $\mathrm{Cd}$ tolerance and its 483 Cd accumulation capacity (Isaure et al., 2015). Interestingly, in non-accumulator Arabidospis lyrata and $\mathrm{Cd}$ non-tolerant Arabidopsis halleri x A. lyrata progenies from Isaure et al. study (Isaure et al., 2015), Cd is coordinated by S atoms only or with a small contribution of $\mathrm{O}$ ligands, which is very similar to what we observed in $S$. melongena 487 (100\% Cd bound to thiols). As mentioned earlier, $\mathrm{Cd}$ chelation by thiol ligands and vacuolar sequestration of these complexes is a known detoxification mechanism in various plants and fungi (Cobbett, 2000; Marentes and Rauser, 2007; Mendoza-Cózatl et al., 2008; Pál et al., 2018; Uraguchi and Fujiwara, 2012; Wawrzyński et al., 2006). Among the non-protein thiol ligands, glutathione is of particular interest. As an antioxidant compound, 492 it plays a major role in the defense against oxidative stress in plants (Cobbett, 2000; Mendoza-Cózatl et al., 2008; Ulrich and Jakob, 2019). Glutathione is also the precursor 494 and building block of phytochelatins (Noctor et al., 2011; Ulrich and Jakob, 2019), which 495 have been identified as Cd chelating agents involved in $\mathrm{Cd}$ detoxification mechanisms 496 (Cobbett, 2000; Szalai et al., 2009). Our results point toward a major role of these 497 detoxification mechanisms in S. melongena. Genetic and cellular studies show that the 498 vacuolar sequestration of $\mathrm{Cd}$ complexed by non-protein thiols are active processes that 499 consume energy to maintain vacuolar to cytoplasmic Cd gradient (Cobbett, 2000; Ulrich 500 and Jakob, 2019). Interestingly, in the dead leaves of S. melongena, the amount of Cd 501 bound to thiol ligands dramatically decreases compared to fresh leaves, with values of 
$40 \%$ total Cd bound to $S$ ligands (Figures 4 and 5), the remaining $\mathrm{Cd}$ being bound to $-\mathrm{O}$

503 ligands (accepted fits with Cd-malate and Cd-tartrate). This is in very good agreement with 504 the existence of an active $\mathrm{Cd}$ detoxification mechanism taking place in S. melongena fresh 505 tissues.

Cd in S. nigrum leaves.

508 As for $S$. melongena, $\mathrm{Cd}$ complexation by thiol ligands plays an important role in $S$. nigrum, with values of $\sim 75 \%$ in the bottom, more mature leaves. Our results suggest that the remaining $\mathrm{Cd}$ in those leaves is bound to inorganic sulfur (Figures 4 and 5). Previous studies reported that Cd may be stored in plants, including Solanum lycopersicum, in a stable high molecular complex that incorporate phytochelatins and sulfides (Collin et al., 513 2014; Pickering et al., 1999; Reese et al., 1992). In fungi, CdS crystallite core coated with 514 phytochelatins were isolated and identified by titration and optical spectroscopy (Bae and 515 Mehra, 1998; Dameron and Winge, 1990). The possibility of a polynuclear Cd cluster with 516 inorganic, bridging sulfides was also suggested by sulfur K-edge EXAFS performed on 517 synthetic Cd-phytochelatin (Pickering et al., 1999). Bae and Mehra proposed that the 518 stability of Cd-phytochelatin complexes is enhanced by the addition of sulfides (Bae and Mehra, 1998). Cadmium detoxification through binding to mineral sulfur has also been observed by $\mathrm{Cd}$ K-edge EXAFS spectroscopy, in the bacterium Stenotrophomonas maltophilia (Pages et al., 2008). We also conclude that the combination of inorganic CdS 522 and $\mathrm{Cd}$ bound to thiols compound observed in S. nigrum mature leaves constitutes a Cd 523 detoxification mechanism and could explain the enhanced Cd accumulation capacity of $S$. 524 nigrum compared to $S$. melongena. In $S$. nigrum younger, top leaves, our results suggest 525 that the same mechanism is involved, as $58 \%$ of $\mathrm{Cd}$ is bound to thiols and $27 \%$ to mineral 526 S. In addition, $\sim 15 \%$ of $\mathrm{Cd}$ is bound to $-\mathrm{O}$ ligands. As the more mature leaves do not show 527 Cd complexation with oxygen ligands, this reinforces our hypothesis that $\mathrm{Cd}$ bound to $\mathrm{O}$ 
528 ligands is a transient form in younger leaves, that could be associated with the 529 translocation and transport of $\mathrm{Cd}$ from the roots to the leaves, where $\mathrm{Cd}$ would eventually 530 be stored bound to S ligands.

\subsection{Environmental implications}

535 Since Cd phytoavailability is tightly linked to its chemical speciation (Cullen and

536 Maldonado, 2013), it is crucial to get direct, experimental access to this parameter. In this 537 context, the developing use of XAS spectroscopy to determine Cd ligands keeps on 538 bringing new information on this metal fate in plants (Huguet et al., 2015; Isaure et al., 539 2015; Wiggenhauser et al., 2020). We reported here, to our knowledge, the first direct 540 determination of $\mathrm{Cd}$ speciation in Solanaceae. We demonstrated that sulfur plays a major 541 role in the detoxification of $\mathrm{Cd}$ in these plants, and that oxygen ligands only take part as 542 transport forms for $\mathrm{Cd}$ translocation. Our findings do not agree with Sun et al. titration543 based hypothesis of a full $\mathrm{Cd}$ complexation with organic acids in $S$. nigrum and $S$. 544 melongena (Sun et al., 2006), which proves that XAS spectroscopy has a lot to offer to 545 understand $\mathrm{Cd}$ distribution in plants. For the first time, a combination of $\mathrm{Cd}$ binding to 546 thiolates and to inorganic sulfur was determined in plants, confirming Salt and 547 collaborators intuition in 2002 (Salt et al., 2002). Cao et al. showed that sulfur fertilizer 548 application in rice reduces Cd uptake and translocation to the grains (Cao et al., 2018). In 549 S. melongena, a similar result was obtained for chromium: high sulfur supply decreases $550 \mathrm{Cr}(\mathrm{VI})$ toxicity (Singh et al., 2017). As we showed that $\mathrm{S}$ is a major agent of $\mathrm{Cd}$ 551 detoxification in S. nigrum and S. melongena, it would be of interest to investigate whether 552 high sulfur supply to these plants may also reduce $\mathrm{Cd}$ toxicity. 


\section{Acknowledgments}

556 This work was supported by a MSCA Individual Fellowship (SPECADIS, 794825) awarded 557 to MLP. E. Doelsch has received funding from the EU Horizon 2020 Framework 558 Programme for Research and Innovation under the Marie Skodowska-Curie actions 559 agreement $\mathrm{N}^{\circ} 795614$. We acknowledge Diamond Light Source for time on Beamline B18 560 under Proposal SP23312. The authors wish to thank D. Gianolo and G. Cibin for their 561 precious help on the B18 beamline, and A.-K. Geiger for her help in the lab. We 562 acknowledge SOLEIL for provision of synchrotron radiation facilities on Beamline SAMBA 563 under Proposal 20190342, and we would like to thank G. Landrot for assistance in using 564 beamline SAMBA. We thank M.P. Isaure for sharing her Cd references EXAFS spectra, 565 and M. Wiggenhauser for helpful discussions. 
Adeleke, R., Nwangburuka, C., Oboirien, B., 2017. Origins, roles and fate of organic acids in soils: A review. South Afr. J. Bot. 108, 393-406.

Bae, W., Mehra, R.K., 1998. Properties of glutathione- and phytochelatin-capped CdS bionanocrystallites. J. Inorg. Biochem. 69, 33-43. https://doi.org/10.1016/S0162-0134(97)10006-X

Baize, D., 1997. Teneurs totales en éléments traces métalliques dans les sols (France). INRA Editions, Paris.

Baker, A., Mcgrath, S., Reeves, R., Smith, J.A.C., 2000. Metal hyperaccumulator plants: a review of the ecology and physiology of a biological resource for phytoremediation of metal-polluted soils. Phytoremediation Contamin Soil Water 85.

Bao, T., Sun, L.-N., Sun, T.-H., 2011a. The effects of Fe deficiency on low molecular weight organic acid exudation and cadmium uptake by Solanum nigrum L. Acta Agric. Scand. Sect. B - Soil Plant Sci. 61, 305-312. https://doi.org/10.1080/09064710.2010.493529

Bao, T., Sun, T., Sun, L., 2011b. Low molecular weight organic acids in root exudates and cadmium accumulation in cadmium hyperaccumulator Solanum nigrum L. and nonhyperaccumulator Solanum lycopersicum L. Afr. J. Biotechnol. 10, 17180-17185.

Barrow, N.J., Gerth, J., Brümmer, G.W., 1989. Reaction kinetics of the adsorption and desorption of nickel, zinc and cadmium by goethite. II Modelling the extent and rate of reaction. J. Soil Sci. 40, 437-450.

Bruemmer, G.W., Gerth, J., Tiller, K.G., 1988. Reaction kinetics of the adsorption and desorption of nickel, zinc and cadmium by goethite. I. Adsorption and diffusion of metals. J. Soil Sci. 39, 37-52.

Cai, Y., Braids, O.C., American Chemical Society (Eds.), 2003. Biogeochemistry of environmentally important trace elements, ACS symposium series. American Chemical Society, Washington, DC.

Cao, Z.-Z., Qin, M.-L., Lin, X.-Y., Zhu, Z.-W., Chen, M.-X., 2018. Sulfur supply reduces cadmium uptake and translocation in rice grains (Oryza sativa L.) by enhancing iron plaque formation, cadmium chelation and vacuolar sequestration. Environ. Pollut. 238, 76-84.

Chamseddine, M., Wided, B.A., Guy, H., Marie-Edith, C., Fatma, J., 2008. Cadmium and copper induction of oxidative stress and antioxidative response in tomato (Solanum lycopersicon) leaves. Plant Growth Regul. 57, 89. https://doi.org/10.1007/s10725-008-9324-1

Chen, Y., Ma, J., Li, Y., Weng, L., 2019. Enhanced cadmium immobilization in saturated media by gradual stabilization of goethite in the presence of humic acid with increasing pH. Sci. Total Environ. 648, 358-366. https://doi.org/10.1016/j.scitotenv.2018.08.086

Cobbett, C.S., 2000. Phytochelatins and Their Roles in Heavy Metal Detoxification. Plant Physiol. 123, 825. https://doi.org/10.1104/pp.123.3.825

Collin, B., Doelsch, E., Keller, C., Cazevieille, P., Tella, M., Chaurand, P., Panfili, F., Hazemann, J.L., Meunier, J.D., 2014. Copper distribution and speciation in bamboo exposed to a high $\mathrm{Cu}$ concentration and $\mathrm{Si}$ supplementation. First Evid. Presence Reduc. Copp. Bound Sulfur Compd. Poaceae Env Pollut 187, 22-30.

Cornu, J.-Y., Deinlein, U., Höreth, S., Braun, M., Schmidt, H., Weber, M., Persson, D.P., Husted, S., Schjoerring, J.K., Clemens, S., 2015. Contrasting effects of nicotianamine synthase knockdown on zinc and nickel tolerance and accumulation in the zinc/cadmium hyperaccumulator Arabidopsis halleri. New Phytol. 206, 738-750. https://doi.org/10.1111/nph.13237

Cullen, J.T., Maldonado, M.T., 2013. Biogeochemistry of Cadmium and Its Release to the Environment, in: Sigel, A., Sigel, H., Sigel, R.K. (Eds.), Cadmium: From Toxicity to Essentiality. Springer Netherlands, Dordrecht, pp. 31-62. https://doi.org/10.1007/978-94-007-5179-8_2

Dameron, C.T., Winge, D.R., 1990. Characterization of peptide-coated cadmium-sulfide crystallites. Inorg. Chem. 29, 1343-1348. https://doi.org/10.1021/ic00332a011

Das, P., Samantaray, S., Rout, G.R., 1997. Studies on cadmium toxicity in plants: A review. Environ. Pollut. 98, 29-36. https://doi.org/10.1016/S0269-7491(97)00110-3

Dharma-wardana, M.W.C., 2018. Fertilizer usage and cadmium in soils, crops and food. Environ. Geochem. Health 40, 2739-2759. https://doi.org/10.1007/s10653-018-0140-x

Doelsch, E., Basile-Doelsch, I., Rose, J., Masion, A., Borschneck, D., Hazemann, J.-L., Saint Macary, H., Bottero, J.Y., 2006. New combination of EXAFS spectroscopy and density fractionation for the speciation of chromium within an andosol. Environ. Sci. Technol. 40, 7602-7608.

Fan, T.W.-M., Lane, A.N., Pedler, J., Crowley, D., Higashi, R.M., 1997. Comprehensive analysis of organic ligands in whole root exudates using nuclear magnetic resonance and gas chromatography-mass spectrometry. Anal. Biochem. 251, 57-68.

Gao, Y., Zhou, P., Mao, L., Shi, W.J., Zhi, Y.E., 2010. Phytoextraction of cadmium and physiological changes in Solanum nigrum as a novel cadmium hyperaccumulator. Russ. J. Plant Physiol. 57, 501-508. https://doi.org/10.1134/S1021443710040072

Gerth, J., Bruemmer, G., 1983. Adsorption and immobilisation of nickel, zinc and cadmium by goethite (. cap alpha.$\mathrm{FeOOH}$ ). 
Gerth, J., Brümmer, G.W., Tiller, K.G., 1993. Retention of Ni, Zn and Cd by Si $\square$ associated goethite. Z. Für Pflanzenernähr. Bodenkd. 156, 123-129.

Hammer, D., Keller, C., McLaughlin, M.J., Hamon, R.E., 2006. Fixation of metals in soil constituents and potential remobilization by hyperaccumulating and non-hyperaccumulating plants: Results from an isotopic dilution study. Environ. Pollut. 143, 407-415. https://doi.org/10.1016/j.envpol.2005.12.008

Han, F., Shan, X., Zhang, S., Wen, B., Owens, G., 2006. Enhanced cadmium accumulation in maize roots-the impact of organic acids. Plant Soil 289, 355-368.

Hasan, Md.K., Ahammed, G.J., Sun, S., Li, M., Yin, H., Zhou, J., 2019. Melatonin Inhibits Cadmium Translocation and Enhances Plant Tolerance by Regulating Sulfur Uptake and Assimilation in Solanum lycopersicum L. J. Agric. Food Chem. 67, 10563-10576. https://doi.org/10.1021/acs.jafc.9b02404

Hasan, Md.K., Ahammed, G.J., Yin, L., Shi, K., Xia, X., Zhou, Y., Yu, J., Zhou, J., 2015. Melatonin mitigates cadmium phytotoxicity through modulation of phytochelatins biosynthesis, vacuolar sequestration, and antioxidant potential in Solanum lycopersicum L. Front. Plant Sci. 6. https://doi.org/10.3389/fpls.2015.00601

Huguet, S., Bert, V., Laboudigue, A., Barthès, V., Isaure, M.-P., Llorens, I., Schat, H., Sarret, G., 2012. Cd speciation and localization in the hyperaccumulator Arabidopsis halleri. Environ. Exp. Bot. 82, 54-65. https://doi.org/10.1016/j.envexpbot.2012.03.011

Huguet, S., Isaure, M.-P., Bert, V., Laboudigue, A., Proux, O., Flank, A.-M., Vantelon, D., Sarret, G., 2015. Fate of cadmium in the rhizosphere of Arabidopsis halleri grown in a contaminated dredged sediment. Sci. Total Environ. 536, 468-480.

Isaure, M.-P., Fayard, B., Sarret, G., Pairis, S., Bourguignon, J., 2006. Localization and chemical forms of cadmium in plant samples by combining analytical electron microscopy and X-ray spectromicroscopy. Spectrochim. Acta Part B At. Spectrosc. 61, 1242-1252. https://doi.org/10.1016/j.sab.2006.10.009

Isaure, M.-P., Huguet, S., Meyer, C.-L., Castillo-Michel, H., Testemale, D., Vantelon, D., Saumitou-Laprade, P., Verbruggen, N., Sarret, G., 2015. Evidence of various mechanisms of Cd sequestration in the hyperaccumulator Arabidopsis halleri, the non-accumulator Arabidopsis lyrata, and their progenies by combined synchrotron-based techniques. J. Exp. Bot. 66, 3201-3214. https://doi.org/10.1093/jxb/erv131

Kubier, A., Wilkin, R.T., Pichler, T., 2019. Cadmium in soils and groundwater: A review. Appl. Geochem. 108, 104388.

Küpper, H., Mijovilovich, A., Meyer-Klaucke, W., Kroneck, P.M.H., 2004. Tissue- and Age-Dependent Differences in the Complexation of Cadmium and Zinc in the Cadmium/Zinc Hyperaccumulator Thlaspi caerulescens (Ganges Ecotype) Revealed by X-Ray Absorption Spectroscopy. Plant Physiol. 134, 748-757. https://doi.org/10.1104/pp.103.032953

Landrot, G., 2018. FASTOSH: a software to process XAFS data for geochemical \& environmental applications. Goldschmidt Abstr. 2018.

Le Bars, M., Legros, S., Levard, C., Chaurand, P., Tella, M., Rovezzi, M., Browne, P., Rose, J., Doelsch, E., 2018. Drastic Change in Zinc Speciation during Anaerobic Digestion and Composting: Instability of Nanosized Zinc Sulfide. Environ. Sci. Technol. 52, 12987-12996. https://doi.org/10.1021/acs.est.8b02697

Li, X., Cui, X., Zhang, X., Liu, W., Cui, Z., 2020. Combined toxicity and detoxification of lead, cadmium and arsenic in Solanum nigrum L. J. Hazard. Mater. 389, 121874. https://doi.org/10.1016/j.jhazmat.2019.121874

Lin, Z., Schneider, A., Sterckeman, T., Nguyen, C., 2016. Ranking of mechanisms governing the phytoavailability of cadmium in agricultural soils using a mechanistic model. Plant Soil 399, 89-107.

Loganathan, P., Vigneswaran, S., Kandasamy, J., Naidu, R., 2012. Cadmium Sorption and Desorption in Soils: A Review. Crit. Rev. Environ. Sci. Technol. 42, 489-533. https://doi.org/10.1080/10643389.2010.520234

Lombi, E., Zhao, F.J., Dunham, S.J., McGrath, S.P., 2000. Cadmium accumulation in populations of Thlaspi caerulescens and Thlaspi goesingense. New Phytol. 145, 11-20.

Lu, L., Tian, S., Yang, X., Peng, H., Li, T., 2013. Improved cadmium uptake and accumulation in the hyperaccumulator Sedum alfredii: the impact of citric acid and tartaric acid. J. Zhejiang Univ. Sci. B 14, 106-114. https://doi.org/10.1631/jzus.B1200211

Maqbool, A., Rizwan, M., Ali, S., Zia-ur-Rehman, M., 2019. Chapter 12 - Plant Nutrients and Cadmium Stress Tolerance, in: Hasanuzzaman, M., Vara Prasad, M.N., Nahar, K. (Eds.), Cadmium Tolerance in Plants. Academic Press, pp. 319-333. https://doi.org/10.1016/B978-0-12-815794-7.00012-6

Marentes, E., Rauser, W.E., 2007. Different proportions of cadmium occur as Cd-binding phytochelatin complexes in plants. Physiol. Plant. https://doi.org/10.1111/j.1399-3054.2007.00960.x

Mendoza-Cózatl, D.G., Butko, E., Springer, F., Torpey, J.W., Komives, E.A., Kehr, J., Schroeder, J.I., 2008. Identification of high levels of phytochelatins, glutathione and cadmium in the phloem sap of Brassica napus. A role for thiol-peptides in the long-distance transport of cadmium and the effect of cadmium on iron translocation. Plant J. 54, 249-259. https://doi.org/10.1111/j.1365-313X.2008.03410.x

Mendoza-Cózatl, D.G., Jobe, T.O., Hauser, F., Schroeder, J.I., 2011. Long-distance transport, vacuolar sequestration, tolerance, and transcriptional responses induced by cadmium and arsenic. Curr. Opin. Plant Biol. 14, 554-562. https://doi.org/10.1016/j.pbi.2011.07.004

Nocito, F.F., Lancilli, C., Dendena, B., Lucchini, G., Sacchi, G.A., 2011. Cadmium retention in rice roots is influenced by cadmium availability, chelation and translocation. Plant Cell Environ. 34, 994-1008. 
Noctor, G., Queval, G., Mhamdi, A., Chaouch, S., Foyer, C.H., 2011. Glutathione. Arab. Book 9, e0142-e0142. https://doi.org/10.1199/tab.0142

Pages, D., Rose, J., Conrod, S., Cuine, S., Carrier, P., Heulin, T., Achouak, W., 2008. Heavy Metal Tolerance in Stenotrophomonas maltophilia. PLoS ONE 3, e1539. https://doi.org/10.1371/journal.pone.0001539

Pál, M., Janda, T., Szalai, G., 2018. Interactions between plant hormones and thiol-related heavy metal chelators. Plant Growth Regul. 85, 173-185. https://doi.org/10.1007/s10725-018-0391-7

Pickering, I.J., Prince, R.C., George, G.N., Rauser, W.E., Wickramasinghe, W.A., Watson, A.A., Dameron, C.T., Dance, I.G., Fairlie, D.P., Salt, D.E., 1999. X-ray absorption spectroscopy of cadmium phytochelatin and model systems. Biochim. Biophys. Acta BBA - Protein Struct. Mol. Enzymol. 1429, 351-364. https://doi.org/10.1016/S0167-4838(98)00242-8

Prasad, M.N.V., 1995. Cadmium toxicity and tolerance in vascular plants. Environ. Exp. Bot. 35, 525-545. https://doi.org/10.1016/0098-8472(95)00024-0

Rauser, W.E., 2003. Phytochelatin $\square$ based complexes bind various amounts of cadmium in maize seedlings depending on the time of exposure, the concentration of cadmium and the tissue. New Phytol. 158, 269-278.

Ravel, B., Newville, M., 2005. ATHENA , ARTEMIS , HEPHAESTUS : data analysis for X-ray absorption spectroscopy using IFEFFIT. J. Synchrotron Radiat. 12, 537-541. https://doi.org/10.1107/S0909049505012719

Reese, R.N., White, C.A., Winge, D.R., 1992. Cadmium-Sulfide Crystallites in Cd- $(\gamma E C)_{n}$ G Peptide Complexes from Tomato. Plant Physiol. 98, 225. https://doi.org/10.1104/pp.98.1.225

Rehr, J.J., Kas, J.J., Vila, F.D., Prange, M.P., Jorissen, K., 2010. Parameter-free calculations of X-ray spectra with FEFF9. Phys. Chem. Chem. Phys. 12, 5503-5513.

Rizwan, M., Meunier, J.-D., Miche, H., Keller, C., 2012. Effect of silicon on reducing cadmium toxicity in durum wheat (Triticum turgidum L. cv. Claudio W.) grown in a soil with aged contamination. J. Hazard. Mater. 209210, 326-334. https://doi.org/10.1016/j.jhazmat.2012.01.033

Robson, T.C., Braungardt, C.B., Rieuwerts, J., Worsfold, P., 2014. Cadmium contamination of agricultural soils and crops resulting from sphalerite weathering. Environ. Pollut. 184, 283-289. https://doi.org/10.1016/j.envpol.2013.09.001

Salt, D.E., Prince, R.C., Pickering, I.J., 2002. Chemical speciation of accumulated metals in plants: evidence from Xray absorption spectroscopy. Microchem. J. 71, 255-259.

Salt, D.E., Prince, R.C., Pickering, I.J., Raskin, I., 1995. Mechanisms of cadmium mobility and accumulation in Indian mustard. Plant Physiol. 109, 1427-1433.

Samardjieva, K.A., Gonçalves, R.F., Valentão, P., Andrade, P.B., Pissarra, J., Pereira, S., Tavares, F., 2015. Zinc Accumulation and Tolerance in Solanum nigrum are Plant Growth Dependent. Int. J. Phytoremediation 17, 272-279. https://doi.org/10.1080/15226514.2014.898018

Sarret, G., 2002. Forms of Zinc Accumulated in the Hyperaccumulator Arabidopsis halleri. PLANT Physiol. 130, 1815-1826. https://doi.org/10.1104/pp.007799

Sarret, G., Smits, E.P., Michel, H.C., Isaure, M.P., Zhao, F.J., Tappero, R., 2013. Use of synchrotron-based techniques to elucidate metal uptake and metabolism in plants, in: Advances in Agronomy. Elsevier, pp. 1-82.

Singh, M., Kushwaha, B.K., Singh, S., Kumar, V., Singh, V.P., Prasad, S.M., 2017. Sulphur alters chromium (VI) toxicity in Solanum melongena seedlings: Role of sulphur assimilation and sulphur-containing antioxidants. Plant Physiol. Biochem. 112, 183-192. https://doi.org/10.1016/j.plaphy.2016.12.024

Sun, R., Zhou, Q., Jin, C., 2006. Cadmium accumulation in relation to organic acids in leaves of Solanum nigrum L. as a newly found cadmium hyperaccumulator. Plant Soil 285, 125-134. https://doi.org/10.1007/s11104-0060064-6

Sun, R., Zhou, Q., Wei, S., 2011. Cadmium Accumulation in Relation to Organic Acids and Nonprotein Thiols in Leaves of the Recently Found Cd Hyperaccumulator Rorippa globosa and the Cd-accumulating Plant Rorippa islandica. J. Plant Growth Regul. 30, 83-91. https://doi.org/10.1007/s00344-010-9176-6

Szalai, G., Kellös, T., Galiba, G., Kocsy, G., 2009. Glutathione as an Antioxidant and Regulatory Molecule in Plants Under Abiotic Stress Conditions. J. Plant Growth Regul. 28, 66-80. https://doi.org/10.1007/s00344-008-90752

Ueno, D., Iwashita, T., Zhao, F.-J., Ma, J.F., 2008. Characterization of Cd Translocation and Identification of the Cd Form in Xylem Sap of the Cd-Hyperaccumulator Arabidopsis halleri. Plant Cell Physiol. 49, 540-548. https://doi.org/10.1093/pcp/pcn026

Ueno, D., Yamaji, N., Kono, I., Huang, C.F., Ando, T., Yano, M., Ma, J.F., 2010. Gene limiting cadmium accumulation in rice. Proc. Natl. Acad. Sci. 107, 16500-16505.

Ulrich, K., Jakob, U., 2019. The role of thiols in antioxidant systems. Free Radic. Biol. Med. 140, 14-27. https://doi.org/10.1016/j.freeradbiomed.2019.05.035

Uraguchi, S., Fujiwara, T., 2012. Cadmium transport and tolerance in rice: perspectives for reducing grain cadmium accumulation. Rice 5, 5. https://doi.org/10.1186/1939-8433-5-5

Uraguchi, S., Watanabe, I., Yoshitomi, A., Kiyono, M., Kuno, K., 2006. Characteristics of cadmium accumulation and tolerance in novel Cd-accumulating crops, Avena strigosa and Crotalaria juncea. J. Exp. Bot. 57, 2955-2965. https://doi.org/10.1093/jxb/erl056 
Vanderschueren, R., De Mesmaeker, V., Mounicou, S., Isaure, M.-P., Doelsch, E., Montalvo, D., Delcour, J.A., Chavez, E., Smolders, E., 2020. The impact of fermentation on the distribution of cadmium in cacao beans. Food Res. Int. 127, 108743. https://doi.org/10.1016/j.foodres.2019.108743

Vogel-Mikuš, K., Arčon, I., Kodre, A., 2010. Complexation of cadmium in seeds and vegetative tissues of the cadmium hyperaccumulator Thlaspi praecox as studied by X-ray absorption spectroscopy. Plant Soil 331, 439-451. https://doi.org/10.1007/s11104-009-0264-y

Vogel-Mikuš, K., Pongrac, P., Kump, P., Nečemer, M., Regvar, M., 2006. Colonisation of a Zn, Cd and Pb hyperaccumulator Thlaspi praecox Wulfen with indigenous arbuscular mycorrhizal fungal mixture induces changes in heavy metal and nutrient uptake. Environ. Pollut. 139, 362-371.

Wang, P., Chen, H., Kopittke, P.M., Zhao, F.-J., 2019. Cadmium contamination in agricultural soils of China and the impact on food safety. Environ. Pollut. 249, 1038-1048. https://doi.org/10.1016/j.envpol.2019.03.063

Wasserman, S.R., 1997. The analysis of mixtures: Application of principal component analysis to XAS spectra. J. Phys. IV 7, C2-203-C2-205.

Wasserman, S.R., Allen, P.G., Shuh, D.K., Bucher, J.J., Edelstein, N.M., 1999. EXAFS and principal component analysis: a new shell game. J. Synchrotron Radiat. 6, 284-286.

Wasylenki, L.E., Swihart, J.W., Romaniello, S.J., 2014. Cadmium isotope fractionation during adsorption to Mn oxyhydroxide at low and high ionic strength. Geochim. Cosmochim. Acta 140, 212-226.

Wawrzyński, A., Kopera, E., Wawrzyńska, A., Kamińska, J., Bal, W., Sirko, A., 2006. Effects of simultaneous expression of heterologous genes involved in phytochelatin biosynthesis on thiol content and cadmium accumulation in tobacco plants. J. Exp. Bot. 57, 2173-2182. https://doi.org/10.1093/jxb/erj176

Wei, S.H., Zhou, Q.X., Wang, X., 2005. Cadmium-hyperaccumulator Solanum nigrum L. and its accumulating characteristics. Huan Jing Ke Xue Huanjing Kexue 26, 167-171.

Wiggenhauser, M., Aucour, A.-M., Bureau, S., Campillo, S., Telouk, P., Romani, M., Ma, J.F., Landrot, G., Sarret, G., 2020. Cadmium Transfer in Contaminated Soil-Rice Systems: Insights from Solid-State Speciation analysis and Stable Isotope Fractionation. Environ. Pollut. 115934. https://doi.org/10.1016/j.envpol.2020.115934

Zhai, L., Liao, X., Chen, T., Yan, X., Xie, H., Wu, B., Wang, L., 2008. Regional assessment of cadmium pollution in agricultural lands and the potential health risk related to intensive mining activities: A case study in Chenzhou City, China. J. Environ. Sci. 20, 696-703. https://doi.org/10.1016/S1001-0742(08)62115-4

Zhou, Q.X., Song, Y.F., 2004. Principles and methods of contaminated soil remediation. Sci. Beijing Chin. 

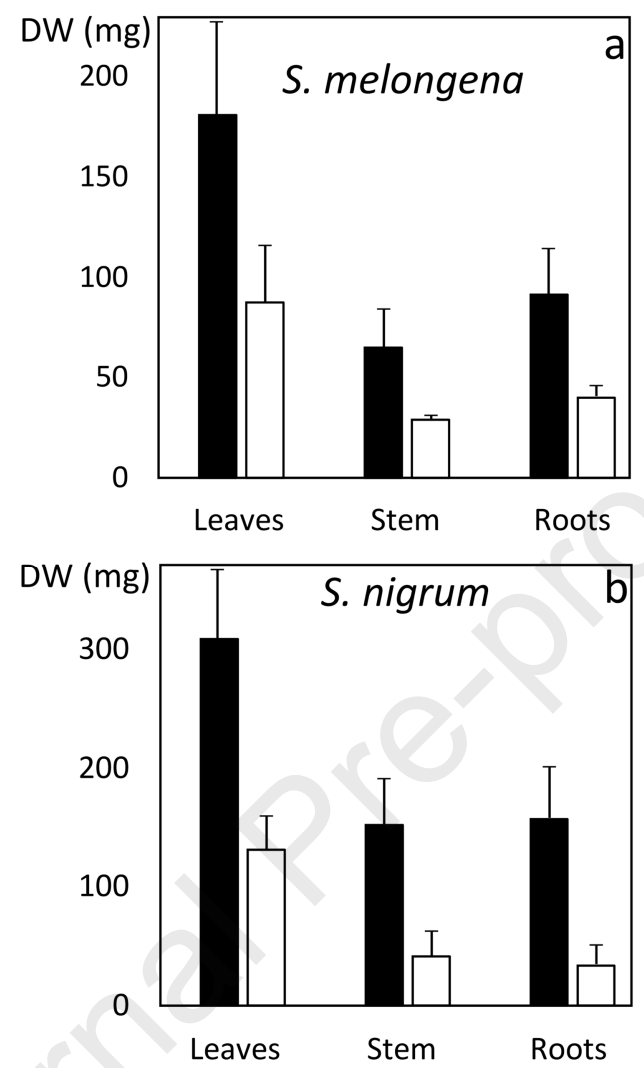

- control soil $\square 100$ mg.kg ${ }^{-1}$ Cd-doped soil

Fig. 1. Dry weight (DW) in milligrams of plant parts from $S$. melongena (a) and $S$. nigrum (b) grown on $100 \mathrm{mg} \cdot \mathrm{kg}^{-1} \mathrm{Cd}$-doped soil and control soil. Error bars are 1 s.d. 


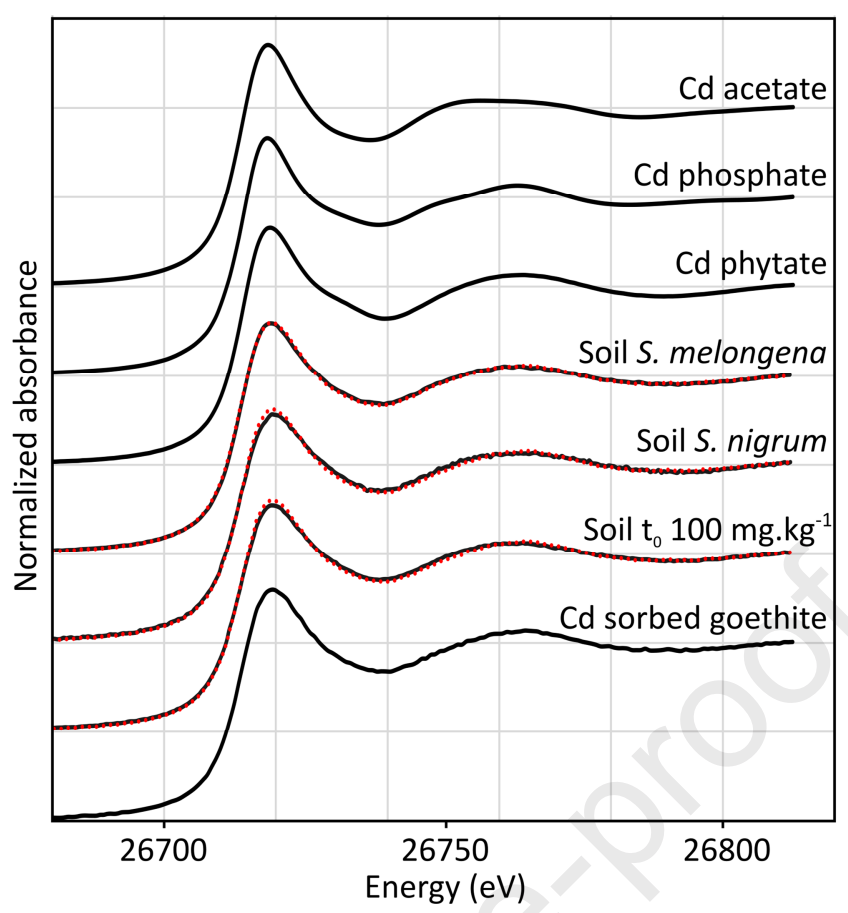

Fig. 2. Cd K-edge XANES spectra of $100 \mathrm{mg} \cdot \mathrm{kg}^{-1} \mathrm{Cd}$ doped pre-culture soil (Soil $t_{0}$ ) and post-culture soils (Soil $S$. melongena and Soil S. nigrum; solid dark grey lines) and their respective reconstructed best fits (LCF; dotted red lines). LCF parameters are given in Supplementary Table S9. Cd K-edge XANES spectra of some relevant $\mathrm{Cd}$ reference compounds for comparison ( $\mathrm{Cd}$ sorbed to goethite, Cd-phytate, Cd-phosphate and Cd-acetate).

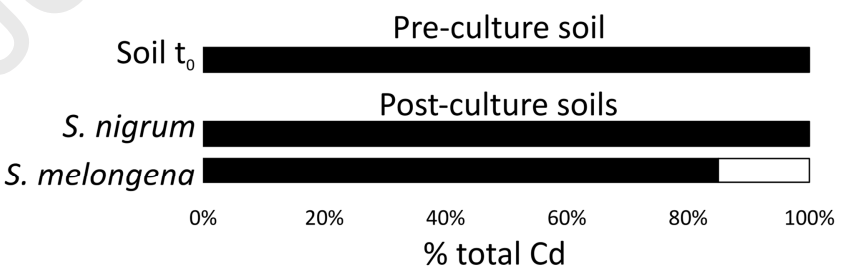

- Cd sorbed goethite $\square$ Cd-O (organic acid)

Fig. 3. Proportion of $\mathrm{Cd}$ species (in \% mole fraction) in pre- and post-culture soils treated with $100 \mathrm{mg} \cdot \mathrm{kg}^{-1} \mathrm{Cd}$, obtained by XANES linear combination fitting. The percentages were normalized to $100 \%$. The uncertainty of each compound proportion was estimated to $\pm 15 \%$. LCF parameters are given in Supplementary Table S9. 

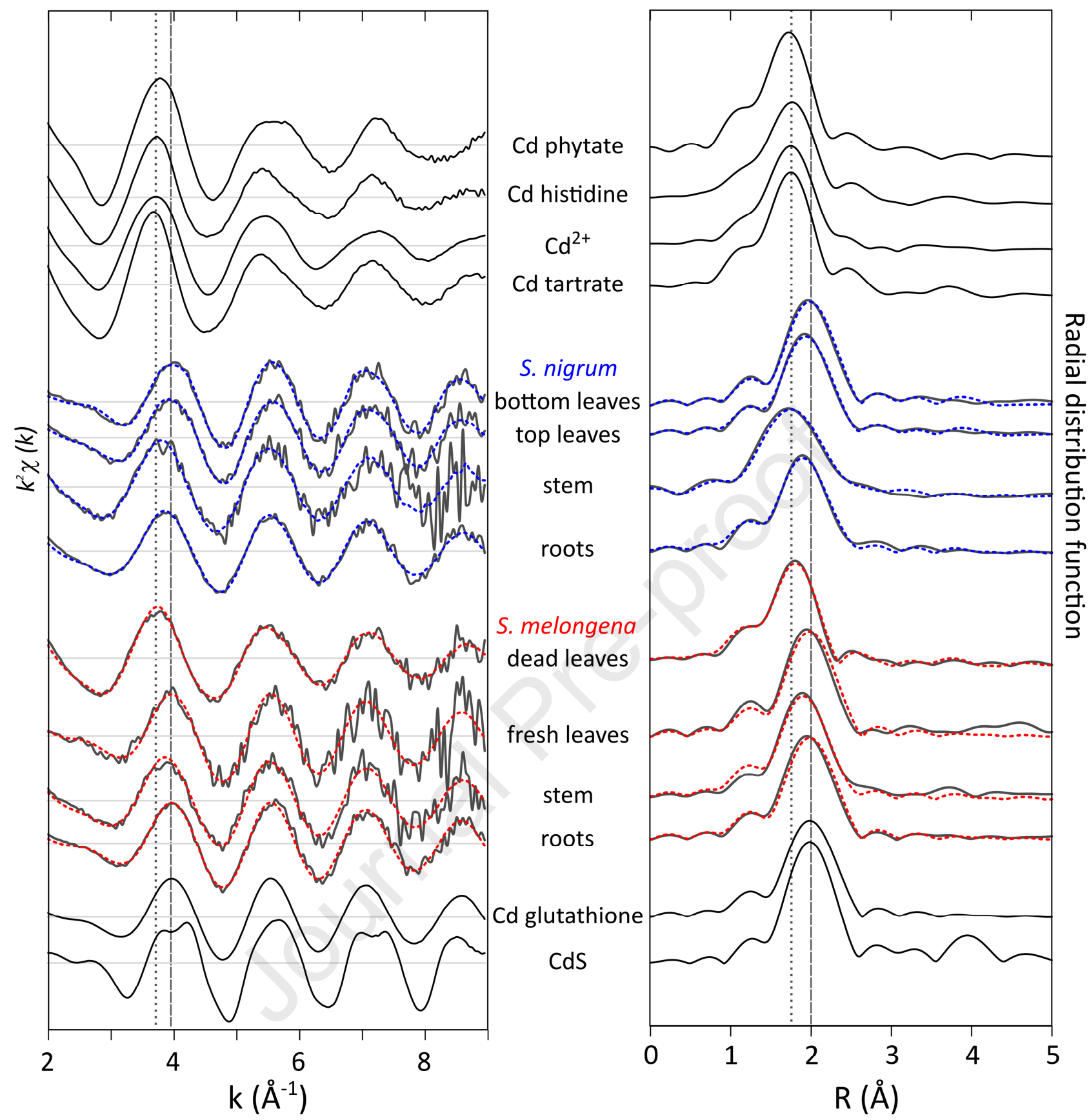

Fig. 4. Cd K-edge EXAFS spectra (left) and Fourier transforms (FT, radial distribution function uncorrected for phase shift functions; right) giving the radial distances of the nearest neighbors to Cd for plant parts of $S$. nigrum and $S$. melongena (dark grey solid lines) after 14 weeks of Cd exposure on a 100 mg.kg-1 Cd-doped soil. Red dotted lines: reconstructed best fits (LCF) for S. melongena EXAFS spectra and associated FT. Blue dotted lines: reconstructed best fits (LCF) for $S$. nigrum EXAFS spectra and associated FT. LCF parameters are given in Supplementary Table S11. Black solid lines: EXAFS spectra and FT of some relevant $\mathrm{Cd}$ reference compounds for comparison. Vertical dotted lines: distance R or wave-number $\mathrm{k}$ associated with $\mathrm{Cd}$ bound to $\mathrm{O}$ atoms in its first shell. Vertical dashed lines: distance $\mathrm{R}$ or wave-number $\mathrm{k}$ associated with $\mathrm{Cd}$ bound to $\mathrm{S}$ atoms in its first shell. 


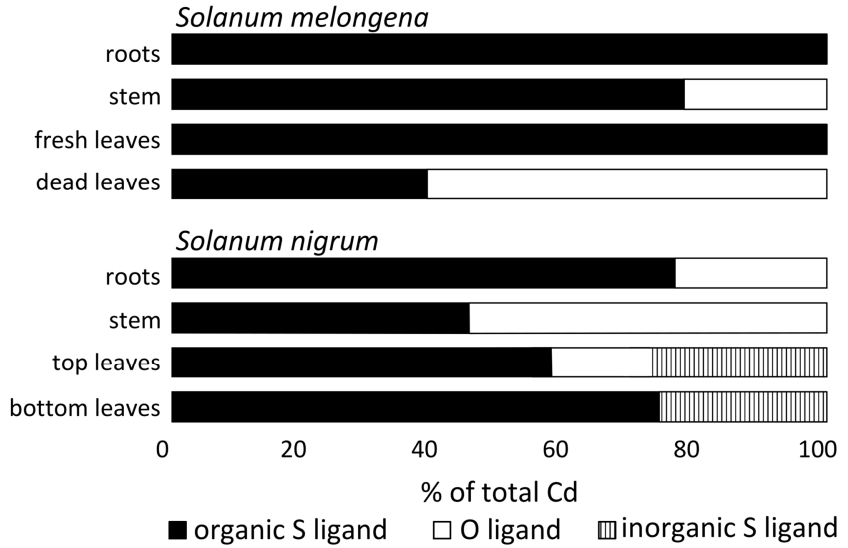

810

Fig. 5. Proportion of Cd species (in \% mole fraction) in S. melongena and $S$. nigrum plant parts (plants grown on a $100 \mathrm{mg} \cdot \mathrm{kg}^{-1}$ Cd-doped soil) obtained by EXAFS linear combination fitting. The percentages were normalized to $100 \%$. The uncertainty of each compound proportion was estimated to $\pm 15 \%$. LCF parameters are given in Supplementary Table S11. 


\section{Highlights}

- X-ray absorption Cd speciation in Solanum nigrum and S. melongena was reported.

- $\mathrm{Cd}$ in the pre- and post-culture clayey loam soils was bound to iron oxyhydroxides.

- In S. melongena roots and fresh leaves, Cd was fully bound to thiol ligands.

- In S. nigrum leaves, Cd detoxification involved binding to thiols and inorganic S.

- In both plants, $\mathrm{Cd}$ transportation involved partial complexation with organic acids. 


\section{Declaration of interests}

$x$ The authors declare that they have no known competing financial interests or personal relationships that could have appeared to influence the work reported in this paper.

$\square$ The authors declare the following financial interests/personal relationships which may be considered as potential competing interests: 